\title{
The Effect of Online Homework Due Dates on College Student Achievement in Elementary Algebra
}

\author{
Joan M. Raines \\ Middle Tennessee State University \\ P.O. Box 16, Murfreesboro, TN 37132, United States \\ Tel: 1-615-898-5554Ｅ-mail: Joan.Raines@mtsu.edu
}

Received: April 23, 2012

Accepted: May 6, 2012

Published: August 1, 2012

doi:10.5296/jse.v2i3.1704

URL: http://dx.doi.org/10.5296/jse.v2i3.1704

\begin{abstract}
This quasi-experimental study examined the use of online homework in a college elementary algebra course to determine if homework due dates made a difference in students' mathematics achievement as measured by unit tests and an end of course final exam. The extent to which homework was completed and possible gender differences in performance were also investigated. Participants in this study were students $(n=58)$ enrolled in three sections of the course during fall 2010 and spring 2011 semesters. The control group consisted of students who had all unit homework due the night before the unit test, and the study group had homework due throughout the unit testing period. Results of a two-way ANOVA revealed no significant differences in test grades between the two groups and an unpaired t-test showed no significant differences in final exam grades. Additionally, gender appeared to have no significant effect on academic performance either.
\end{abstract}

Keywords: online homework, homework, online courseware, textbook-based courseware 


\section{Introduction}

Homework has been a component of most students' educational experiences for years, particularly in mathematics. The influence of homework on learning has been documented for students in elementary school through college. Research studies on homework conducted to determine if relationships exist between homework and student achievement indicate that homework in general is extremely beneficial for students (Paschal, Weinstein \&Walberg, 1984; Bruce \& Singh, 1996; Cooper, Robinson \& Patall, 2006).

Numerous studies also document student understanding of mathematics concepts when using computer-based learning or course management systems (Kulik \& Kulik, 1991; Nguyen \& Kulm, 2005; Dillard-Eggers, Wooten, Childs \& Coker, 2008). According to the 2001 National Survey of Information Technology in U.S. Higher Education, approximately one-fifth of all college courses use course management tools (Green, 2001), andat least 100,000 students submitted homework online while attending on ground classes (Bonham, Deardorff\&Beichner, 2003). A growing trend in college mathematics courses is the use oftextbook-based computer courseware to supplement or replace traditional objects of learning such as homework and textbooks. These mathematics courses are implementing an online format for homework instead of collecting the traditional homework papers from students.

\section{Literature Review}

\section{Does Homework Help?}

Through an examination of nearly 120 empirical studies, Cooper (1989) found homework has many positive effects on achievement and learning. Among these are the immediate effects of increased understanding and better retention of material, and the long-term benefits of improvement in students' study skills and attitudes. Cooper also found potential negative effects of homework that include loss of interest in the material if homework requires too much time and polarization of opportunities for students from different socioeconomic backgrounds.

Walberg, Paschal, and Weinstein (1985) conducted a synthesis of 15 empirical studies on the effects of homework on learning and found when homework was assigned without any type of feedback, it appeared to raise typical student learning that was at the $50^{\text {th }}$ percentile to the $60^{\text {th }}$ percentile. But when it was graded or contained teacher comments, homework appeared to raise learning from the $50^{\text {th }}$ percentile to the $79^{\text {th }}$ percentile. Through their research, Walberg, Paschal, and Weinstein concluded homework had substantial effects on students' learning. Using data from the 1988 National Education Longitudinal Study, Bruce and Singh (1996) discovered that homework not only improved student's grades, but also improved their scores on standardized tests.

Keith (1982) used a sample of 20,364 high school seniors from the 1980 National Center for Education Statistics' (NCES) High School and Beyond Longitudinal Study to investigate the effects of time spent on homework on high school seniors' achievement, as measured by grades. In his quantitative study, multiple regression analysis confirmed that an increase in 
the amount of time spent on homework had a positive effect on students' grades. This study found that more time spent on homework resulted in higher achievement. Similarly, results from Keith and Cool's (1992) quantitative study using 25,875 high school students from the 1980 and 1982 NCES High School and Beyond Longitudinal Studies revealed that time spent on homework had an important and meaningful influence on achievement and learning. In his review of literature, Cooper (1994) also discovered that out of 50 studies correlating time spent on homework with achievement, 43 showed that students who did more homework had better achievement. Gradelevel too had an influence on homework's effectiveness. Cooper also found that for high school students, homework increased academic performance and had a significant effect on achievement.

Cartledge and Sasser's (1981) quantitative study examined the mathematics achievement of 30 college algebra students randomly assigned to a homework or no homework group. These students received the same instruction from the same teacher and were given the same tests, including a pretest and posttest. Results froman analysis of the posttest indicated that students who were given homework assignments were likely to learn more than those not given any homework. Cartledge and Sasser concluded there was a tendency for homework to improve achievement. In a meta-analysis involving research on the effects of homework, Cooper, Robinson, and Patall (2006) found six studies comparing students who were assigned homework with those who were not. The results showed homework could be effective in improving scores on unit or chapter tests in various subjects. Additionally,Cooper, Robinson, and Patall observed that in 35 samples of students used in correlational studies, 27 found a positive link between homework and achievement.

Homework is necessary and its importance has been established by many individual studies and meta-analyses (Walberg, Paschal \& Weinstein, 1985; Cooper, 1994; Cooper \& Valentine, 2001). Overall, these studies and others suggest that students who do homework generally outperform students who do not do homework on some measure of achievement such as subject or standardized tests.

\section{Is Web-based Homework Effective?}

In addition to research looking at homework's effect on student achievement, severalindividual studies and meta-analyses have examined the effects of computer-based instruction and web-based homework on student learning. While some of these studies have shown computer-based work did not significantly improve student performance on specific measures of academic achievement, many others concluded students do derive benefits from completing online assignments.

Kulik and Kulik (1991) conducted a meta-analysis of 254 evaluation studies that compared student learning in classes taught with and without computer-based instruction. Of those studies, 248 suggested that the average student from computer-based instruction classes would outperform $62 \%$ of the students in the control groups on exams given at the end of instruction. Computer-based instruction raised exam scores by 0.3 standard deviations, a moderate but significant effect. Thus, Kulik and Kulik concluded that computer-based instruction produced positive effects on achievement and learning. In a study by Hirsch and 
Weibel (2003), students in web-based sections of general calculus at Rutgers University improved their grades on the final exam by $4 \%$, a small but statistically significant change. These 1175 students were split into a control group that did only written homework and an experimental group that also submitted homework online. The researchers also found the correlation between the number of attempts and the percentage of problems solved was 0.944, which suggested students persevered until the problem was solved. Nguyen and Kulm's (2005) quantitative study on web-based instruction involved 95 students in six mathematics classes from two middle schools in southeast Texas. The students were randomly assigned to one of two groups, web-based practice or traditional paper and pencil practice, and were given the same homework assignments, pretest, and posttest. Nguyen and Kulm's results revealed the mathematics achievement of the students using web-based practice was significantly higher on a posttestthan that of those using paper and pencil.These results also indicated web-based practice could improve student learning, aid in self-motivation in learning mathematics, and allow students to have independent practice.

Dillard-Eggers, Wooten, Childs, and Coker (2008) evaluated the impact of homework done online on students' performance in an accounting principles class. Surveys of 223 students were conducted to determine their perceptions of the effectiveness of online homework in enhancing their learning. Regression analysis revealed that the course grade was positively affected by the extent of homework done. The researchers concluded online homework increased student performance and that students believed using online homework was an effective method of study. The quantitative research study by Hodge, Richardson, and York (2009) investigated the degree to which web-based homework affected student motivation and perceptions of learning mathematics. Survey data was collected from 1333 students enrolled in a college algebra course, of which 1125 had previously used web-based homework in a mathematics course. The researchers found a majority of the students were motivated to complete more homework using a web-based learning system than completing traditional paper and pencil problems. Additionally, one-third of the students in their study felt web-based homework increased their mathematical learning.Examination of student surveys regardingonline homework and web-based practice has shownthat students are willing to persist and spend the time it takes togain better understanding of the mathematical knowledge required to solve problems (Nguyen \& Kulm, 2005; Hirsch \& Weibel, 2003).

Hauk and Segalla (2005) also found that online homework was at least as effective as traditional paper and pencil homework for students in college algebra. Their study examined survey data and test scores from 644 students enrolled in 19 sections of college algebra at a large university in the western United States. Survey results showed $65 \%$ of the students in the seven sections doing paper and pencil homework turned it in, while $78 \%$ of the students doing homework online completed their work. Hauk and Segalla found no statistically significant difference in achievement as measured by performance gains from pretest to posttest. Similarly, Bonham, Beichner, and Deardorff (2001) discovered web-based homework led to neither a significant improvement nor a significant reduction in student learning. Their research project was carried out with 220 students in an introductory calculus-based physics course and 120 students in an algebra-based course with experienced instructors teaching the courses back-to-back on the same days with everything similar except 
how homework was completed. The study compared the performance of students using online homework to those submitting their work on paper, and found students doing homework online consistently performed slightly better on tests but the difference was not statistically significant.

White's (2006) quantitative study examined final exam scores of 193 students enrolled in finite mathematics at three of sixteen centers at a Florida college during fall 2004 and spring 2005 semesters. Her study compared the final exam scores and final course grades of students who used web-based courseware with those who did not. White found a statistically significant difference in performance between the two groups. Results of an ANOVA indicated the final exam scores for those using the online courseware were significantly higher than those not using the courseware. Reporting on the results of case studies that integrated textbook-based courseware into mathematics courses, Speckler $(2007,2008)$ statedthat the courseware improved students' success rates and increased levels of success in subsequent mathematics courses. Furthermore, when online homework was assigned, it appeared to increase student achievement and improve retention rates. Speckler also reported students were motivated to do more homework and were engaged in active learning when using the courseware.

When examining results from the implementation of a new web-based learning environment, Mavrikis and Maciocia (2003) found it had no adverse effect on students' performance. Furthermore, they discovered that immediate feedback was one of the most important issues in web-based learning and practice. Zerr (2007) also examined an online homework system created to provide an attempt-feedback-reattempt process for studentsin first-semester calculus at the University of North Dakota. He found student attitudes were very positive toward the system, and the students believed it was a productive use of their time. Moreover, Zerr compared student outcomes on quizzes and exams and discovered that the more successful students were with online homework, the better they performed overall. He concluded that online homework was helping students in the way it was designed to. Immediate feedback encourages low-achieving students to practice more, builds confidence in students unsure about their understandings of mathematical concepts and procedures, and allows students to master material by correcting their own mistakes.

Using online homework is one way to enrich students' experiences in mathematicsand other courses.Testone (2005) found online homework appeared to "improve student learning and provide a better homework experience than typical textbook assignments" (p 2). The previousstudies and others(Nguyen, Hsieh,\& Allen, 2006; Beal, Walles, Arroyo, \& Woolf, 2007; Fletcher, Hawley,\&Piele, 1990) have been conducted to examine the effects of web-based or online homework on student achievement and attitudes with a majority concluding students do derive some type of benefits from completing homework in this manner.

\section{Purpose}

The use of online homework is growing due mainly to reports of its effectiveness. The number of students usingonline courseware and course management systems has increased dramatically since their inception. Seventy-two percent of college students reported having 
taken a class that incorporated the use of a course management system, and nearly $85 \%$ of students surveyed stated the use of technology improved their learning (Kvavik\& Caruso, 2005).

The mathematics course used in this study is the equivalent of a developmental elementary algebra course, and was selected because math in general presents a great challenge for the students who are required to take it. In the state of Tennessee, many incoming college students are at risk for academic failure. A high percentage of these students enter school unprepared for college-level math, and are required to complete developmental coursework first (TBR, 2005).Testone (2005) noted that students who were required to use textbook-basedcomputer courseware succeeded in developmental math courses at a higher rate than students who did not use the courseware. Thus, the intent of this study was to determine if online homework and when it is assigned would benefit those students who are already at risk. Three research questions were posed:

1. Did specific dates for when homework was due make a difference in students' mathematics learning on unit tests?

2. Did specific dates for when homework was due make a difference in students' overall performance in Essentials of Mathematics (elementary algebra)?

3. Did any differences exist in students' mathematical performance based on gender?

The study examined the use of online homework in an elementary algebra course to determine if homework due dates made a difference in students' mathematics learning and achievement as measured by unit tests and an end of course final exam. Relatively few, if any, studies have examined how online homework is assigned and how specific due dates might affect students' performance in mathematics courses. The extent to which homework was completedwas also investigated.

\section{Institutional Setting}

The study took place at a four-year open admissions, coeducational, state-funded institution located in an urban area in Tennessee. The university offers both comprehensive undergraduate and select graduate degree programs, andhas been classified as a doctoral/research-intensive institution. Student enrollment in fall 2010 was 26,430; of which 6,489 were freshmen. The average ACT mathematics subscore was 20.5 with an average overall composite score of 22. There were 1767 freshmen with ACT math subscores in the range of 16-20 (50.06\%) and 202 with math subscores in the range of $11-15(5.72 \%)$. Fifty-three percent of students enrolled at the university were female and $47 \%$ male.

\section{Participants}

The participants in this study were all students enrolled in three sections of Essentials of Mathematics ( $N=73$ ) offered during fall 2010 and spring 2011 semesters. Since students self-registered for the course, random assignment to the control or study group could not be made.The final sample used for this research was 58 participants, and of those students 27 were male and 31 female.The study included only those students who completed the course 
and took the departmental final exam used in the analysis of the study.Out of the students who completed the course, 10 had previously taken the class and were repeating it. Students were in one of two groups: the control group, which consisted of students who took the course fall 2010 and had all unit homework due the night before the unit test $(n=39)$,and the study group, students who took the course spring 2011andhad homework due throughout the unit testing period

( $n=19$ ). All students received the same instruction through traditional lecture in the classroom with the same instructor, were assigned the same homework problems, and took the same unit tests andfinal exam. The only difference between the groups was thedue dates forhomework completion.

\section{Course Details}

Essentials of Mathematics is a three credit-hour course (which students receive elective credit for)that is essentially a developmental elementary algebra course, and covers topics which are normally covered in that course, but also includes a technology component. These topics include order of operations, solving linear equations and inequalities, graphing lines, writing equations of lines, exponents and scientific notation, polynomials, and factoring. The course is the first in a two-semester sequence and serves as an introduction to learning mathematics and helping students acquire the foundations and skills necessary to be successful in college-level mathematics. Students are required to take this course if they have a high school deficiency in mathematics orACT mathematics subscore of 15 or 16.Additional placement testing is required for some students and their scores could also place them in the course.

All sections of the course require the use of MyMathLab, a customizable onlinetextbook-based courseware system developed by Pearson Education. Students purchase an access code, are given an instructor course code, and then enroll in the course. MyMathLab can be accessed 24 hours a day from any computer that has an internet connection. The courseware includes an interactive online version of the textbook so studentshad the option of purchasing the textbook or using the online e-book.

Homework assignments can be created from an online exercise bank that correlates to textbook exercises, and instructors can also create their own custom questions. The questions are algorithmically generated,which allows for unlimited practice and mastery. Students in this study worked a mixture of multiple choice and free response questions. While doing homework, students have several resources available to further assist them. The "Help Me Solve This" feature walks students step by step through the same problem they are trying to solve, then gives them a similar problem to do on their own. Figure 1 illustrates the "View an Example" feature which allows students to work on a problem while viewing a worked out example of the same type of problem they are attempting to solve. 


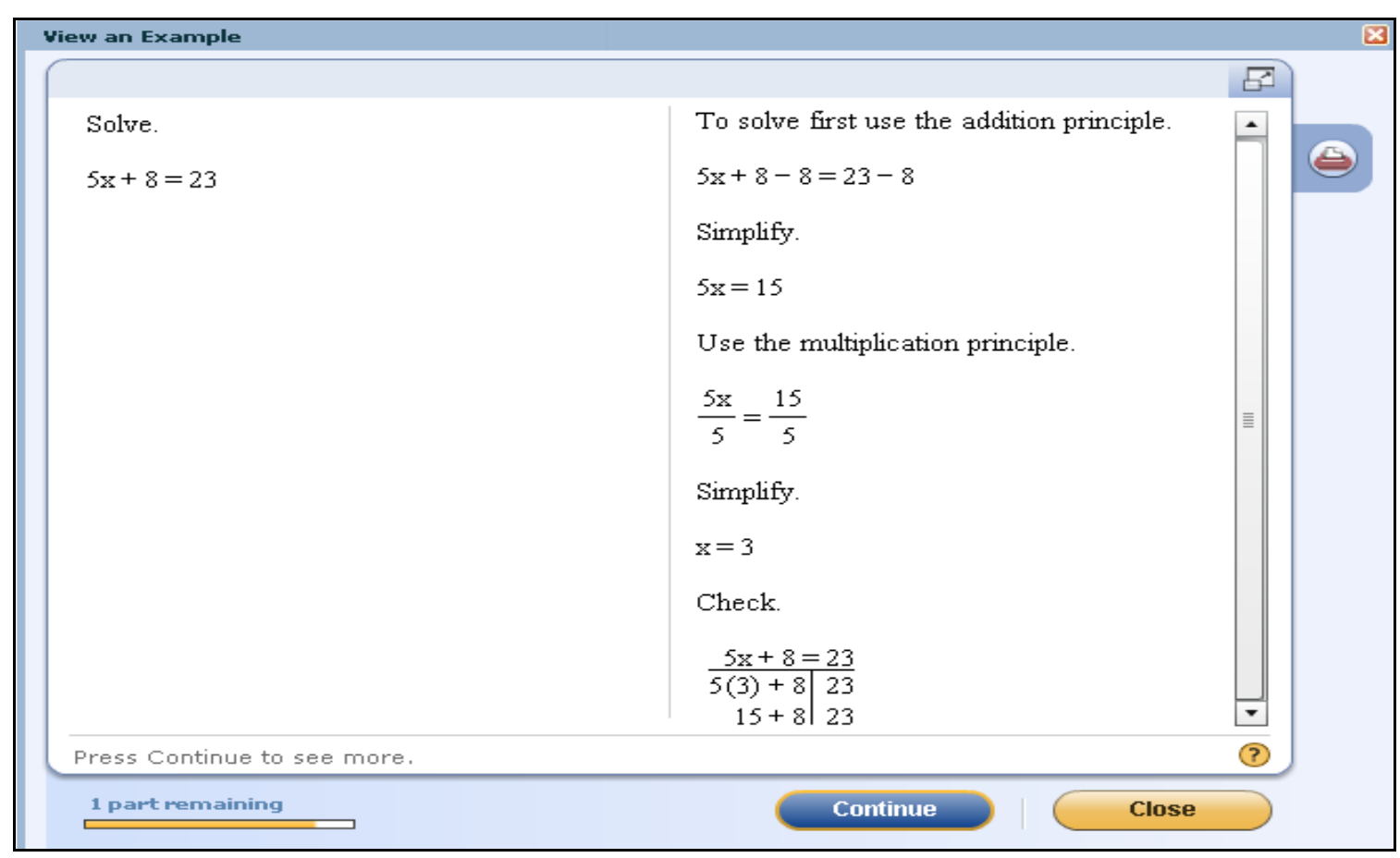

Figure 1.

Figure 1. Screenshot of a sample problem in "View an Example” from Pearson Education's MyMathLab. Problem from Elementary and Intermediate Algebra: Graphs and Models, 3 rd ed., by M.L. Bittinger, D.J. Ellenbogen, and B.L. Johnson. Copyright 2008 by Pearson Education, Inc.Reprinted with permission.

As students go through homework problems and enter solutions, they receive immediate feedback for each attempt. If a problem is solved incorrectly, hints and encouragement to try again are given as shown in Figures 2 and 3. Another feature available is "Similar Exercise", which gives students a homework problem similar to one they were just working on. This allows them to continue working a problem until they completely understand the concept and also lets them improve their grades by working a problem until they get it correct. An added benefit for students is the vast multimedia library. While working on homework, students can access animated presentations, video lectures, and the interactive online textbook (see Figure 4). 


\section{$(-\infty, \infty)$}

(Type your answer in interval notation.)

For what $x$-value(s) is $f(x)=1$ ? Select the below and, if necessary, fill in the answer your choice.

\section{$x=4,6$}

(Use a comma to separate answer
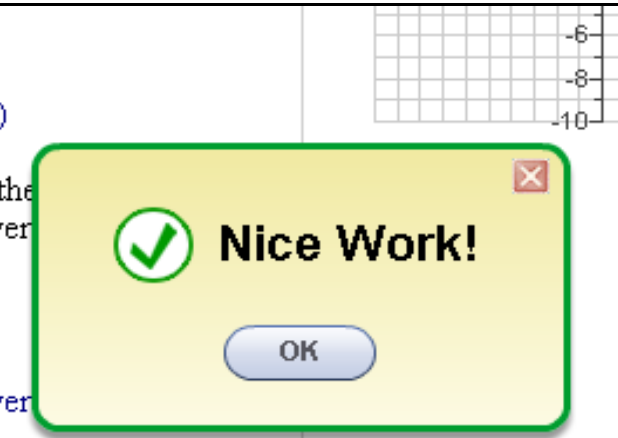

There is no value of $\mathrm{x}$ for which $\mathrm{f}(\mathrm{x})=1$.

Figure 2.

Figure 2.Screenshot of immediate feedback for correct solutions from Pearson Education's MyMathLab. Problem from Elementary and Intermediate Algebra: Graphs and Models, $3^{\text {rd }}$ ed., by M.L. Bittinger, D.J. Ellenbogen, and B.L. Johnson. Copyright 2008 by Pearson Education, Inc.Reprinted with permission.

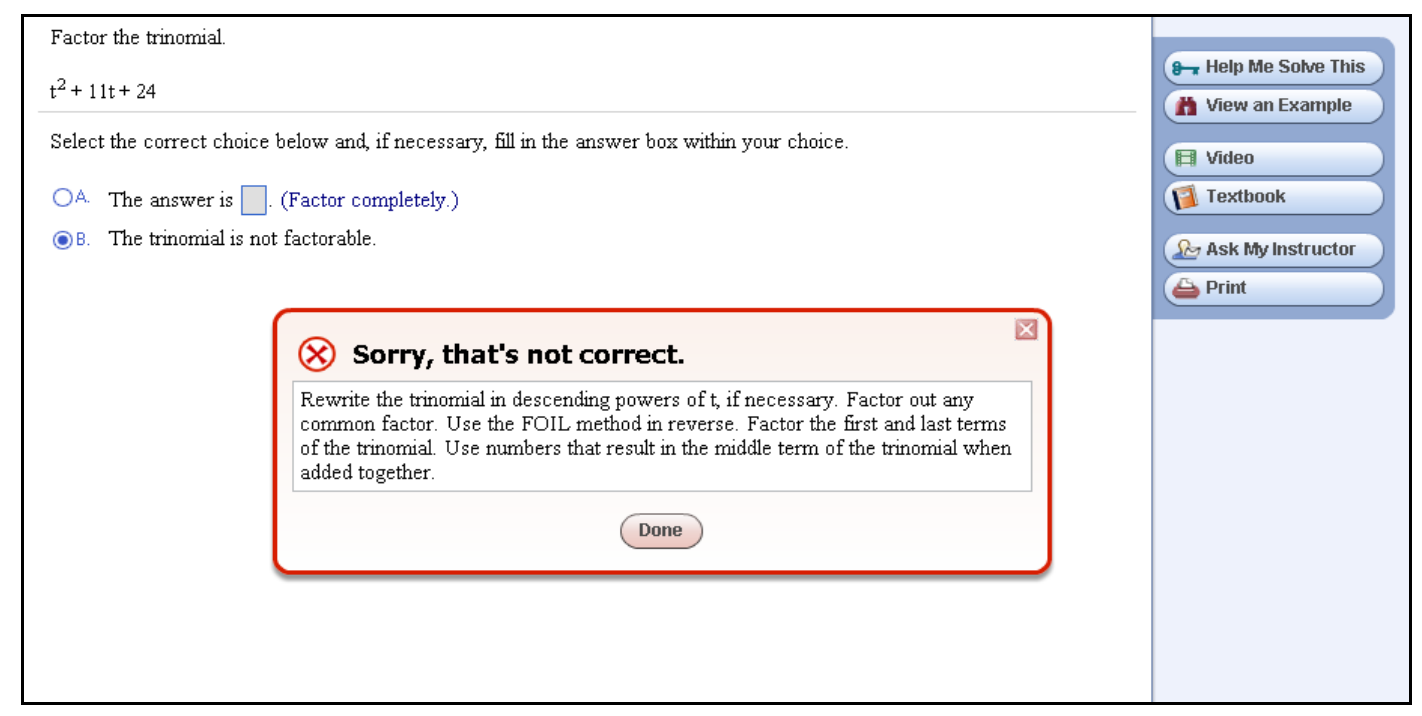

Figure 3.

Figure 3. Screenshot of hint received when a problem is incorrect from Pearson Education's MyMathLab. Problem from Elementary and Intermediate Algebra: Graphs and Models, $3^{\text {rd }}$ ed., by M.L. Bittinger, D.J. Ellenbogen, and B.L. Johnson. Copyright 2008 by Pearson Education, Inc. Reprinted with permission. 


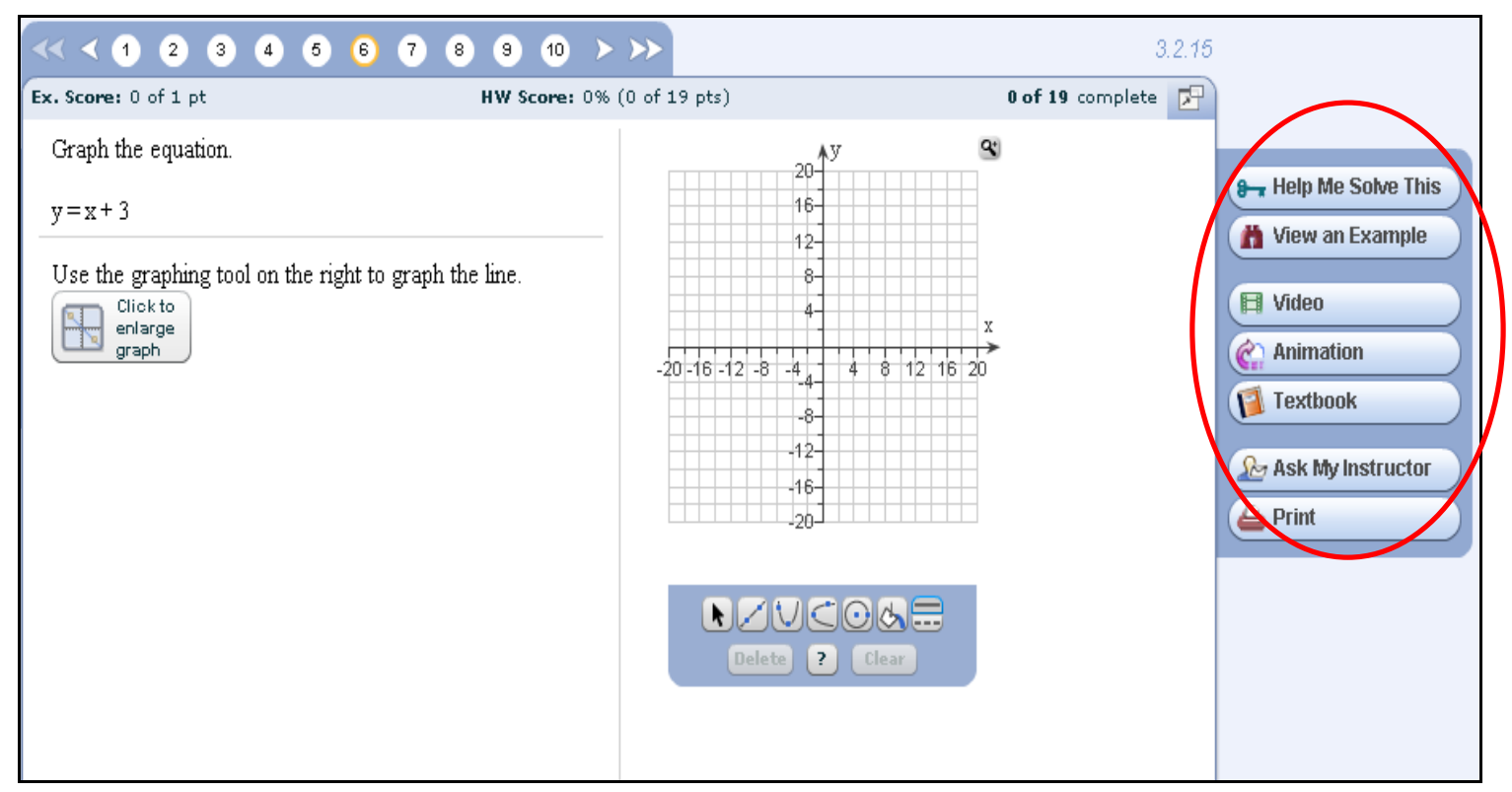

Figure 4.

Figure 4.Screenshot of multimedia options available when solving problems from Pearson Education's MyMathLab.Problem from Elementary and Intermediate Algebra: Graphs and Models, $3^{\text {rd }}$ ed., by M.L. Bittinger, D.J. Ellenbogen, and B.L. Johnson. Copyright 2008 by Pearson Education, Inc. Reprinted with permission.

This web-based courseware provides tutorials and practice with immediate, nonjudgmental feedback and can be used to teach, reinforce concepts, and review. Students are able to individualize their own instruction which provides support in their learning and mastering the content of the course.

\section{Instrumentation}

Mathematics learning was defined as scores on the unit tests and overall performance/achievement was defined as scores on the Essentials of Mathematics final exam. The final exam was a departmental exam given to all students taking the course and was developed by a committee of faculty in the department to match the objectives of the course. This provided face validity for the exam; however, it was not reviewed for content validity or reliability. The final exam consisted of 40 multiple choice questions. The unit tests were constructed by the instructor of the course with content matching the objectives of the course. Unit tests were a mixture of multiple choice and free response questions and each consisted of 20-25 questions. The notations used in the study are: HBT $=$ the control group whose homework was due the night before the unit test and HTT = the study group whose homework was due throughout the unit testing period.

\section{Data Analysis}

Initial data analysis was descriptive and included means and standard deviations for homework, unit tests grades, and final exam scores.Scores were omitted for students who did not take the final exam and complete the course. Seventy-one students took the pretest (50 
from the control group and 21 from the study group). Of these 71 students, 58 took the final exam. Table 1 shows the distribution of the 58 participants by group and gender.

Table 1. Distribution of Participants

\begin{tabular}{llcc}
\hline & Female & Male & Total \\
\hline HBT & 18 & 21 & 39 \\
HTT & 13 & 6 & 19 \\
Total & 31 & 27 & 58 \\
\hline
\end{tabular}

After verifying that the assumptions of analysis of variance were met, a two-way ANOVA was run to determine if there were significant differences in mathematics learning between the two groups.The dependent variable was the unit test grade and the factors were the group and test number. Unpaired t-tests were also conducted to determine whether significant differences existed in homework averages and final exam scores between the two groups along with any differences by gender. Additionally, paired t-tests were performed to determine significant differences in the pretest and final exam scores for each group.Assumptions for the t-tests were verified. StatView statistical software was used for the quantitative data analysis with an alpha $=.05$ level of significance.

\section{Results and Discussion}

Since intact groups of students were used, an unpaired t-test using pretest scores as the dependent variable was carried out to determine if there were any considerable differences between the groups from the outset. The results revealed $(\mathrm{t}=-1.967, \mathrm{p}>.05)$ no significant differences existed; thus, the study began with homogeneous groups.

The overall mean homework score for studentsin the HBT group was 86.5

(SD = 13.94); students in the HTT group had anoverall mean homework score of 85.4

$(\mathrm{SD}=13.74)$. Table 2 shows the unit homework $(\mathrm{HW})$ and test averages for these two groups of students. A comparison of the overall homework averages between the two groups was conducted using an unpaired t-test. The dependent variable was the student's homework average. The results showed $(\mathrm{t}=.271, \mathrm{p}>.05)$ no significant difference in the homework averages between the two groups. Accordingly, student performance on homework was not significantly affected by when the homework was due to be completed.

Homework completion for each group was also reviewed. It was discovered that students in the HBT group with overall homework averages of $\mathrm{C}$ or below waited until the day homework was due to try to complete all of the assignments. These students ended up with 
low or no grades on incomplete assignments. The majority of students with overall A and B homework averages worked on homework throughout the unit testing period and did not wait until the last day homework was due to complete it. Homework completion was different for the HTT group. They could not procrastinate and let the amount of homework pile up; they had specific due dates for each assignment during the unit test period. Students in this group with low overall homework averages would often forget they had assignments due and would end up with low grades or no grade at all. Overall, 41 of the students $(70.7 \%)$ in both groups combined had overall homework averages of an A or B. Due to the way the course management system keeps track of time spent on homework, there was no way to accurately determine how much time students actually spent on homework.

Table 2. Homework and Test Averages by Group

\begin{tabular}{cll}
\hline & HBT Averages & HTT Averages \\
\hline Unit 1 & & \\
HW & 94.6 & 95.3 \\
Test & 77.2 & 78.7 \\
Unit 2 & \\
HW & 83.2 & 79.3 \\
Test & 80.4 & 76.1 \\
Unit 3 & & \\
HW & 81.3 & 73.5 \\
Test & 68.8 & 73.3 \\
Unit 4 & & \\
HW & 88.8 & 81.7 \\
Test & 78.7 & 79.4 \\
Unit 5 & & \\
HW & 78.1 & 69.9 \\
Test & 57.8 & \\
\hline
\end{tabular}

For the first research question, a two-way ANOVA was run to examine whether specific homework due dates made a difference in students' mathematics learning as measured by unit tests. Examination of the interaction line plot (see Figure 5) for test grades reveals the HTT group had higher test averages than the HBT group on every test except one. However, results of the two-way ANOVA revealed there were no significant differences for test grades $(\mathrm{F}=.484, \mathrm{p}>.05)$ between the two groups of students. It appears that how online homework is assigned in regards to when it is due does not influence student achievement as measured by test grades. 


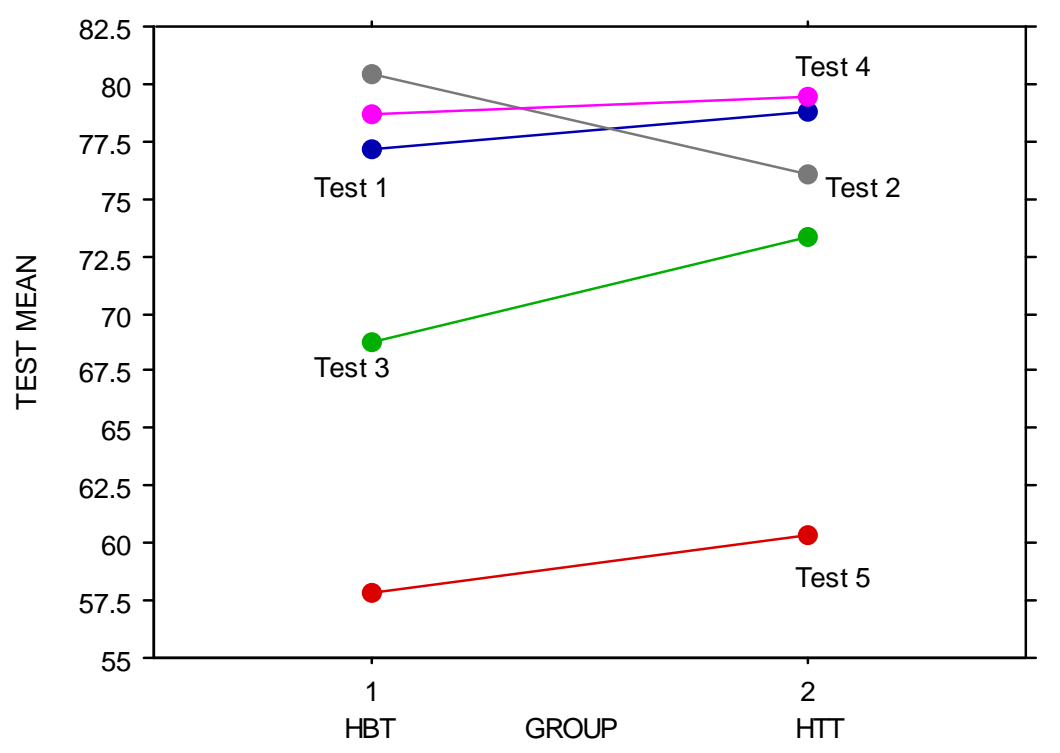

Figure 5. Interaction line plot for test grades.

For the second research question, an unpaired t-test was performed in order to compare differences in final exam grades between the two groups. The dependent variable was the final exam grade with the group as the grouping variable. The test $(t=-.327, p>.05)$ did not yield any results indicating there was a significant difference in the final exam scores between the two groups. The HTT group did have a higher overall mean final exam score of 77 (SD = 14.23) compared to $75.6(\mathrm{SD}=14.83)$ for the HBT group. Yet, when homework is assigned to be due does not significantly affect student performance in Essentials of Mathematics as measured by final exam grades.

The pretest and final exam taken by all students covered the topics they received instruction over during the semester. All students showed improvement to some extent from pretest to final exam. Students in the HBT group had a mean score of 36.4 (SD = 16.33) on the pretest and 75.6 on the final exam. The HTT group had a mean score of 45.3 (SD = 15.55) on the pretest and 77 on the final exam. Analysis of paired t-tests for each group as well as the combined sample revealed significant differences between pretest and final exam scores:

$\mathrm{t}=-13.449, \mathrm{p}<.0001$ for the HBT group, $\mathrm{t}=-8.138, \mathrm{p}<.0001$ for the HTT group, and

$\mathrm{t}=-15.532, \mathrm{p}<.0001$ for the combined group. Each group scored significantly higher on the final exam than on the pretest,indicating mathematics achievement in the course was significantly higher at the end of the course, which was expected.

A student successfully completes Essentials of Mathematics with an end of course grade of C or above. Anything less is considered unsuccessful and students must take the course again the following semester. Tables 3and 4 compare end of course grades for all sections of the course at the university for the fall 2010 and spring 2011 semesters.These figures represent all students who registered for the course and include those students who registered and never 
attended or stopped attending class, but did not officially withdraw. All instructors are required to use MyMathLab and assign online homework, but the extent to which this is done is left up to the individual instructor. Consequently, how much and when homework is assigned varies section by section. For fall, 66\% of the HBT group successfully completed the course compared to $70.6 \%$ university wide; while $73.9 \%$ of the HTT group was successful in the spring compared to $60.4 \%$ university wide.

Table 3. Grade Distribution for Essentials of Mathematics by Group, Fall 2010

\begin{tabular}{lll}
\hline & HBT & All Other University Sections \\
\hline A & 11 & 151 \\
B & 10 & 161 \\
C & 12 & 120 \\
F & 15 & 167 \\
W & 2 & 13 \\
\hline
\end{tabular}

Table 4. Grade Distribution for Essentials of Mathematics by Group, Spring 2011

\begin{tabular}{lll}
\hline & HTT & All Other University Sections \\
\hline A & 4 & 51 \\
B & 4 & 79 \\
C & 9 & 68 \\
F & 5 & 111 \\
W & 1 & 19 \\
\hline
\end{tabular}

A number of studies have reviewed gender differences in relation to homework and found females tend to spend more time on homework than males and expend greater effort on it (Mau \& Lynn, 2000; Cooper, Robinson,\& Patall, 2006; Rogers \&Hallam, 2006). Additionally, Mau and Lynn (2000) found consistently and significantly higher correlations between homework and test scores for females than males. Examining homework averages and final exam grades by gender revealed $81.5 \%$ of males and $90.3 \%$ of females had an overall homework average of A, B, or C. Males had an overall mean homework grade of 84.4 $(\mathrm{SD}=13.62)$ and females $87.7(\mathrm{SD}=13.91)$. To address the third research question, an unpaired t-test discovered

$(\mathrm{t}=-0.915, \mathrm{p}>.05)$ no significant difference existed in the homework averages (dependent variable) due to gender (grouping variable). The final exam grades showed similar results. Females had a mean final exam grade of $77.2(\mathrm{SD}=12.38)$ and males 74.8 (SD = 16.82). Unpaired t-test results $(\mathrm{t}=-0.617, \mathrm{p}>.05)$ also revealed no significant differences in the final 
exam grades due to gender. Twenty-one males (77.8\%) and 28 females (90.3\%) successfully completed the course.

In general, the HBT group had higher homework averages and the HTT group had higher test averages. After examining the data, when homework was assigned to be due had no significant effect on test grades or final exam grades. This is not to say that homework does not influence achievement. Other factors should also be examined. Differences could be due to other variables. Time of day and length of time in class could affect some outcomes. The HBT classes met for an hour and twenty-five minutes in the afternoon two days a week; while the HTT class met for fifty-five minutes in the morning three days a week. It is also interesting to note that on the day the second test was given to the HTT group, the instructor had to miss class and a different instructor gave the test. This event could have had an effect on performance. Additionally, no correlations were found between students repeating the course and those students taking the course for the first time.

A more complete assessment of when online homework is assigned with respect to mathematics achievement will require more replications with larger sample sizes and with different mathematics courses. Online homework could affect student performance differently in a college-level math course as opposed to a developmental math course. Further studies need to be conducted to determine what influence online homework does have on mathematics achievement and if there are other ways to use online homework to improve students' success.

\section{Limitations}

Data were drawn from a relatively small sample at a single institution so these findings may have limited generalizability. Although important, the limitation does not reduce the study's usefulness in understanding how assignment of online homework influences subsequent academic performance.Since all sections of the course require the use of an online courseware system, no comparisons could be made between students'assigned online homework versus traditional paper and pencil homework or no homework at all. Additionally, the results may not apply to courses that use online courseware in different ways such as hybrid courses or course redesigns.

\section{Conclusion}

This study compared the mathematical performance of students who had online homework due either the night before a unit test or throughout the unit testing period. Results of the study revealed there were no significant differences in unit test or final exam grades between the two groups of students.The findings support that students perform equally well regardless of when homework is due, and thus do not provide a clear conclusion for setting specific homework due dates. It appears that as long as students are completing homework before they take a test, performance is not significantly affected. Furthermore, gender seems to have no significant effect on mathematical performance. Both males and females had similar levels of achievement. 
Students responded positively to completing homework online and felt they benefited from the immediate feedback received when completing problems. They also felt that being able to work similar exercises until they understood where they went wrong gave them confidence in their skills. Many of the students in the study preferred to have their homework due the night before the unit test because they felt that working the assigned homework problems helped them review.

Online homework can serve a variety of important purposes in the educational process. Working online has been shown to motivate students to complete homework leading to mastery of mathematical concepts. It does appear online homework has many benefits, and its effects on student performance and achievement should be examined more extensively along with assigning specific due dates for homework completion.

\section{References}

Beal, C.R., Walles, R., Arroyo, I., \& Woolf, B.P. (2007). On-line tutoring for math achievement testing: A controlled evaluation.Journal of Interactive Online Learning, 6(1), 43-55.

Bonham, S., Beichner, R., \& Deardorff, D. (2001). Online homework: Does it make a difference?The Physics Teacher, 39, 293-296.http://dx.doi.org/10.1119/1.1375468

Bonham, S.W., Deardorff, D.L., \& Beichner, R.J. (2003). Comparison of student performance using web and paper-based homework in college-level physics. Journal of Research in Science Teaching, 40(10), 1050-1071. http://dx.doi.org/10.1002/tea.10120

Bruce, F.A., \& Singh, K. (1996).Academic achievement: A model of school learning for eighth grade students. Research in Middle Level Education Quarterly, 19(3), 95-111.

Cartledge, C.M., \& Sasser, J.E. (1981). The effect of homework assignments on the mathematics achievement of college students in freshman algebra. Retrieved from ERIC database. (ED206495)

Cooper, H. (1989). Synthesis of research on homework. Educational Leadership, 47(3), 85-91.

Cooper, H. (1994). Homework research and policy: A review of literature. Retrieved from http://carei.coled.umn.edu/rp/Summer94/homework/html

Cooper, H., Robinson, J.C., \& Patall, E.A. (2006). Does homework improve academic achievement? A synthesis of research, 1987-2003. Review of Educational Research, 76, 1-62. http://dx.doi.org/10.3102/00346543076001001

Cooper, H., \& Valentine, J. C. (2001).Using research to answer practical questions about homework. Educational Psychologist, 36, 143-153.http://dx.doi.org/10.1207/S15326985EP3603_1

Dillard-Eggers, J., Wooten, T., Childs, B., \& Coker, J. (2008).Evidence on the effectiveness of on-line homework. College Teaching Methods and Styles Journal, 4(5), 9-16. 
Fletcher, J. D., Hawley, D. E., \& Piele, P. K. (1990). Costs, effects, and utility of microcomputer assisted instruction in the classroom. American Education Research Journal, 27, 783-806.

Green, K.C. (2001, October). eCommerce comes slowly to the campus. The Campus Computing Project. Retrieved from http://www.campuscomputing.net/sites/

www.campuscomputing.net/files/2001-CCP.pdf

Hauk, S., \& Segalla, A. (2005). Student perceptions of the web-based homework program WeBWork in moderate enrollment college algebra classes. Journal of Computers in Mathematics and Science Teaching, 24(3), 229-253.

Hirsch, L., \& Weibel, C. (2003). Statistical evidence that web-based homework helps. FOCUS: Newsleter of the Mathematical Association of America, 23(2), 14.

Hodge, A., Richardson, J.C., \& York, C.S. (2009). The impact of a web-based homework tool in university algebra courses on student learning and strategies. MERLOT Journal of Online Learning and Teaching, 5, 618-629.

Keith, T.Z. (1982). Time spent on homework and high school grades: A large-sample path analysis. Journal of Educational Psychology, 74, 248-253. http://dx.doi.org/10.1037/0022-0663.74.2248

Keith, T.Z., \& Cool, V.A. (1992). Testing models of school learning: Effects of quality of instruction, motivation, academic coursework, and homework on academic achievement. School Psychology Quarterly, 7, 207-226. http://dx.doi.org/10.1037/h0088260

Kulik, C.C., \& Kulik, J.A. (1991). Effectiveness of computer-based instruction: An updated $\begin{array}{lllll}\text { analysis. Computers in Human } & \text { Behavior, }\end{array}$ http://dx.doi.org/10.1016/0747-5632(91)90030-5

Kvavik, R. B., \& Caruso, J. B. (2005). ECAR study of students and information technology, 2005: Convenience, connection, control, and learning. Retrieved from EDUCAUSE Center for Applied Research website: http://net.educause.edu/ir/library/pdf/ers0506/rs/ERS0506w.pdf

Mau, W.C., \& Lynn, R. (2000). Gender differences in homework and test scores in mathematics, reading and science at tenth and twelfth grade. Psychology, Evolution \& Gender, 2, 119-125. http://dx.doi.org/10.1080/14616660050200904

Mavrikis, M.,\&Maciocia, A. (2003, June). Incorporating assessment into an interactive learning environment for mathematics.MSOR Maths-CAA series. Retrieved from http://mathstore.ac.uk/repository/mathscaa_jun2003.pdf

Nguyen, D.M., Hsieh, Y.J., \& Allen, G.D. (2006). The impact of web-based assessment and practice on students' mathematics learning attitudes. Journal of Computers in Mathematics and Science Teaching, 25, 251-279. 


\section{Macrothink}

Journal of Studies in Education

ISSN 2162-6952

2012, Vol. 2, No. 3

Nguyen, D.M., \& Kulm, G. (2005). Using web-based practice to enhance mathematics learning and achievement. Journal of Interactive Online Learning, 3(3), 1-16.

Paschal,R.A., Weinstein, T. \& Walberg, H.J. (1984). The effects of homework on learning: A quantitative synthesis. The Journal of Educational Research, 78(2), 97-104.

Rogers, L., \& Hallam, S. (2006). Gender difference in approaches to studying for the GCSE among high-achieving pupils. Educational Studies, 32, 59-71. http://dx.doi.org/10.1080/03055690500415985

Speckler, M.D. (2007). Making the grade, version 2.0: A report on the success of MyMathLab in higher education math instruction. Retrieved from Pearson Education website:http://www.pearsoned.com/RESRPTS_FOR_POSTING/HIGHER_ED_RESEARCH _STUDIES/makingthegrade2.pdf

Speckler, M.D. (2008). Making the grade: A compendium of data-driven case studies on the effectiveness of MyMathLab and MathXL.Retrieved from Pearson Education website: http://www.mymathlab.com/sites/default/files/makingthegrade_v3.pdf

Tennessee Board of Regents. (2005). Focus on access. Postsecondary Education Policy Series. Retrieved from http://fp.tbr.edu/academic_affairs/ news/ Access\%20Policy\%20Paper.pdf

Testone, S. (2005). Using publisher resources to assist developmental mathematics students. Research and Teaching in Developmental Education, 21(2). Retrieved from http://findarticles.com/p/articles/mi_qa4116/is_200504/ai_n13502964/

Walberg, H.J., Paschal, R.A., \& Weinstein, T. (1985).Homework's powerful effects on learning. Educational Leadership, 42(7), 76-79.

White, J.A. (2006). Significant differences in student performance between students who do and do not utilize coursecompass. Florida Scientist, 69, 236-241.

Zerr, R. (2007). A quantitative and qualitative analysis of the effectiveness of online homework in first-semester calculus. Journal of Computers in Mathematics and Science Teaching, 26(1), 55-73. 